International Journal of Child, Youth and Family Studies (2015) 6(2): 181-185

\title{
INTRODUCTION TO THE SPECIAL ISSUE ON THE POLITICAL ECONOMY OF CHILDREN'S HEALTH
}

\author{
Toba Bryant and Dennis Raphael, Guest Editors
}

\begin{abstract}
A political economy approach to children's health considers how the economic and political systems of a jurisdiction influence the public policies that shape children's health. It moves beyond the concrete and observable to look at the societal structures and processes that distribute the material and social resources to families and children that can either support or threaten children's health. This special issue presents a number of articles from Canada, Norway, the United Kingdom, and the United States that show how profoundly important these issues are to understanding and acting to improve children's health. As such, these articles provide a useful counterpoint to prevailing notions of children's health, which all too often are focused solely on the creation and delivery of services and attempts to change health-related behaviours. While these other issues are important, it is essential to identify and act to modify the too-frequently neglected structures and processes of society that create the public policies that shape the essential social determinants of children's health.
\end{abstract}

Keywords: children's health, political economy, social inequalities, health inequalities, public policy, social determinants of health

Toba Bryant, Ph.D. is an Assistant Professor at the Faculty of Health Sciences, University of Ontario Institute of Technology, 2000 Simcoe Street North, Oshawa, Ontario, Canada, L1H 7K4. Telephone: (905) 721-8668, ext. 2697. E-mail: toba.bryant@uoit.ca

Dennis Raphael, Ph.D. is a Professor of Health Policy and Management at the School of Health Policy and Management at York University, 4700 Keele Street, Toronto, Ontario, Canada, M3J 1P3. Telephone: (416) 736-2100, ext. 22134. E-mail: draphael@yorku.ca 
This special issue of the International Journal of Child, Youth and Family Studies (IJCYFS) focuses on what critical social scientists call the "story behind the story," the societal economic and political structures and processes that shape the health of children. It is increasingly recognized that the health of populations and the health inequalities that exist amongst these populations are shaped by what the World Health Organization (WHO) calls the social determinants of health. The WHO (2015) defines the social determinants of health:

The social determinants of health are the conditions in which people are born, grow, live, work and age. These circumstances are shaped by the distribution of money, power and resources at global, national and local levels.

Despite conceptual and empirical work on the social determinants of health and increasing acceptance of their importance by researchers and health advocates, there has been virtually no penetration of the concept into public policy activity in Canadian and American jurisdictions. This lack of penetration is apparent at the federal, provincial/territorial and state, as well as municipal levels. This is especially troubling as it is becoming clear that the primary mediators between societal structures and processes and their translation into the social determinants of health are public policies. Public policies directly affect the distribution of the social determinants of health, which then go on to shape the health of children. More disturbing is that these social determinants of health apparently go on to affect children's health as adults even if the quality of the social determinants of health they experience improves during their adolescence and adult years.

People who work directly with children, both in clinical settings as well as in agency and community settings, have a critical role to play in identifying and advocating public policies that improve the quality and equitable distribution of the social determinants of health. Most immediately they need to recognize that social determinants of health play a consequential role in shaping clients' needs and designing appropriate services to respond to these needs. Additionally, those who work with children are in the best situation to advocate for public policies that will improve the living circumstances that both children and their parents experience. Service providers need to become involved in having their voices heard as advocates for public policy that promotes, rather than threatens, children's health. Unfortunately, like most citizens, many service providers do not understand the public policy process and how public policies are made. They lack understanding about how to advocate and work the political system to help bring about such policy change. Moreover, awareness of the importance of having a social determinants perspective on children's health is frequently lacking. And some, not unlike many citizens, are thoroughly disengaged from politics.

We are of the firm belief that knowledge about the social determinants of children's health and political advocacy will be more effective when advocates have a more mature understanding of the forces that drive public policy-making in Canada and elsewhere. It has become apparent that arguments stating the obvious, such as the benefits for children, families, and communities of high quality affordable child care, seem to have little resonance among policy-makers in Canada, for instance. Part of our goal is to make explicit why this may be the case. The answer may be in the different levels of influence and power that different sectors corporate and business, organized labour, civil society - have when issues of public policy arise. 
International Journal of Child, Youth and Family Studies (2015) 6(2): 181-185

Put simply, nowadays in Canada, the U.K., and the U.S.A., children and their families, especially those who are economically vulnerable, appear to have virtually no influence on the development of public policy. This appears to be less the case in Norway.

The answer to this state of affairs is the building of political and social movements consisting of service providers, parents, and other concerned citizens that will literally force public policy-makers to address these issues that shape the health of children. The political economy approach serves many of these purposes. A political economy approach makes explicit the structures and processes that shape public policy. These include competing sectors such as the corporate and business sectors, the organized labour sector, and civil society. If the imbalance amongst these sectors becomes too great then public policy in the service of the majority of Canadians becomes less likely. What is needed is a movement that rectifies these imbalances in such a manner that public policy is made in the service of children's health rather than threatening children's health. We believe in action that will make children's health a priority for governments and societies. Hopefully the articles in this special issue on the political economy of children's health will assist in this task.

\section{Overview of the Special Issue}

\section{The Articles}

This special issue is organized in three sections: Concepts and Processes; Public Policy, Children's Services and Children's Health; and Moving Towards Action. In the first section, Dennis Raphael's article, The Parameters of Children's Health: Key Concepts from the Political Economy of Health, provides an overview of concepts from the political economy approach and places these into a model of how power and influence in society come to shape the social determinants of children's health, and eventually the health of children themselves. He makes the argument that current imbalances in power and influence have contributed to the rather mediocre portrait of children's health in Canada.

Stephen Bezruchka's article, Early Life or Early Death: Support for Child Health Lasts a Lifetime, provides an exhaustive presentation of the processes by which living conditions come to shape the health of children. He goes on to document how these effects then persist to shape their health as adults. The article provides a timely counterpoint to the dominant discourse that making or not making "healthy choices" are at the root of health and illness. Bezruchka then provides recommendations for providing the conditions that will support the health of children rather than threaten it.

As the title of their article, opening the second section, states, Anca Gaston, Sarah Edwards, and Jo Ann Tober find that Maternity Leave and Child Care Arrangements During The First 12 Months of Life are Associated with Children's Development Five Years Later. Importantly, they situate their study and findings within the context of Canadian public policy developments regarding maternal leave. Most mothers take some leave but few had access to licensed child care. Those unable to take leave saw their children doing less well at age 5. Implications for public policy are provided. 
Patrizia Albanese and Ann Rauhala in their article, A Decade of Disconnection: Child Care Policies in Changing Economic Times in the Canadian Context, report on two studies of media coverage and women's experiences of child care in Canada. In the first project, they analyse media coverage of child care issues with particular attention to the extent to which women's voices are presented in media reports on child care. The second project presents the voices of mothers of young children on the difficulties finding appropriate child care for their children.

Stephanie Petrie’s article, “Commodifying” Children: The Impact of Markets in Services for Children in the United Kingdom, explores the marketization of children's services and its impact on children's health and well-being in Britain. In tracing the shift from the welfare state to welfare markets, she specifically discusses the political trajectory that led to this radical change in U.K. welfare. She concludes with an overview of the impact of austerity policies that exclude many children from welfare markets, and the implications for all children in the U.K.

In the third section (Moving Towards Action), Toba Bryant's article, Parameters of Change: Public Policy Models and Processes, identifies the main approaches for making sense of how public policy is made. Understanding the assumptions of each approach is especially important as these models may or may not be appropriate for promoting specific forms of public policy in particular political and economic environments. Bryant concludes that the political economy approach towards public policy changes accurately captures many of the key issues associated with promoting children's health in Canada and elsewhere through public policy action.

In his article, Health Impact Assessment, Municipal Development Practices, and Children's Health, Robert Rattle creates a compelling portrait of how municipal planning decisions can come to shape children's health. He provides details of how a re-siting of a hospital from a downtown to suburban area can have multiple effects upon children's health, most of them negative. Rattle makes the case that municipal planning activities are a source of children's health but assessing the health impacts of these activities is frequently overlooked. The article provides an argument for instituting health impact assessments of public policy activities that are not currently seen as having any impacts on children's health.

Elisabeth Fosse and Marit Helgesen's article, How Can Local Governments Level the Social Gradient in Health Among Families with Children? The Case of Norway, considers how municipalities can reduce social inequalities among families with children. In contrast to the current situation in Canada, the U.K., or the U.S., the Norwegian National government has introduced a number of policies to reduce health inequalities, to be accomplished by a Health in All Policies approach. Municipalities are responsible for the implementation of these policies. Using mixed methods, Fosse and Helgesen examine the extent to which Norwegian municipalities have implemented public health and health promotion policies that can reduce the social inequalities that lead to health inequalities among families with children. 
International Journal of Child, Youth and Family Studies (2015) 6(2): 181-185

\section{The Implications}

The articles in this volume make explicit what is normally left implicit: public policy has a profound effect on children's health. These public policies range from those most obviously related to children's health such as child care and the provision of social services to those less commonly considered such as municipal planning and poverty prevention. Since the making of public policy is shaped by prevailing political ideologies and the influence of powerful sectors, it is important to make explicit what these ideologies and forces may be. Once identified, such barriers can be responded to in the service of creating public policy that promotes children's health, rather than threatens it.

\section{Conclusion}

The aim of this special issue is to transform the reader's way of thinking about children's health and the means by which it can be promoted. The articles contained within this special issue move beyond the obvious and observable to explore the less frequently examined societal structures and processes that shape the social determinants of health. If readers gain a new appreciation of these larger forces shaping children's health and the means of overcoming barriers to promoting children's health, then we will have been successful in our aim. At the end of the day, the effects of the social determinants of children's health require us to consider what kind of society we want, that is, how nurturing and supportive of children our societies will be. This will require political will on the parts of governments to invest in programs and services that support all children. This is occurring in Norway. It is not occurring in Canada, the United Kingdom, or the United States.

\section{Reference}

World Health Organization. (2015). Social determinants of health. Retrieved from http://www.who.int/social_determinants/en/. 